\title{
Comparison of UVB and UVC irradiation disinfection efficacies on Pseudomonas Aeruginosa biofilm
}

\author{
Argyraki, Aikaterini; Markvart, M.; Nielsen, Anne; Bjarnsholt, T.; Bjørndal, L.; Petersen, Paul Michael
}

\section{Published in:}

Proceedings of SPIE

Link to article, DOI:

$10.1117 / 12.2225597$

Publication date:

2016

Document Version

Peer reviewed version

Link back to DTU Orbit

Citation (APA):

Argyraki, A., Markvart, M., Nielsen, A., Bjarnsholt, T., Bjørndal, L., \& Petersen, P. M. (2016). Comparison of UVB and UVC irradiation disinfection efficacies on Pseudomonas Aeruginosa biofilm. In Proceedings of SPIE (Vol. 9887). [988730] SPIE - International Society for Optical Engineering. https://doi.org/10.1117/12.2225597

\section{General rights}

Copyright and moral rights for the publications made accessible in the public portal are retained by the authors and/or other copyright owners and it is a condition of accessing publications that users recognise and abide by the legal requirements associated with these rights.

- Users may download and print one copy of any publication from the public portal for the purpose of private study or research.

- You may not further distribute the material or use it for any profit-making activity or commercial gain

- You may freely distribute the URL identifying the publication in the public portal 


\title{
Comparison of UVB and UVC irradiation disinfection efficacies on Pseudomonas Aeruginosa (P. aeruginosa) biofilm
}

\author{
A. Argyraki $*^{\mathrm{a}}$, M. Markvart ${ }^{\mathrm{b}}$, Anne Nielsen $^{\mathrm{c}}$, T. Bjarnsholt ${ }^{\mathrm{c}, \mathrm{d}}$, L. Bjørndal ${ }^{\mathrm{b}}$, P. M. Petersen ${ }^{\mathrm{a}}$ \\ ${ }^{a}$ Department of Photonics Engineering, Technical University of Denmark, Frederiksborgvej 399, \\ DK-4000, Roskilde, Denmark \\ ${ }^{\mathrm{b}}$ Cariology and Endodontics, Department of Odontology, Faculty of Health Science, University of \\ Copenhagen, Nørre Allé 20, DK-2200, Copenhagen N, Denmark \\ ${ }^{c}$ Department of Immunology and Microbiology, Costerton biofilm Center, Faculty of Health \\ Science, University of Copenhagen, Blegdamsvej 3B, DK-2200 Copenhagen N, Denmark \\ ${ }^{\mathrm{d}}$ Department of Clinical Microbiology, Rigshospitalet, Juliane Maries vej 22, 2100 Copenhagen $\varnothing$, \\ Denmark
}

\begin{abstract}
Disinfection routines are important in all clinical applications. The uprising problem of antibiotic resistance has driven major research efforts towards alternative disinfection approaches, involving light-based solutions. Pseudomonas aeruginosa $(P$. aeruginosa) is a common bacterium that can cause skin, soft tissue, lungs, kidney and urinary tract infections. Moreover, it can be found on and in medical equipment causing often cross infections in hospitals. The objective of this study was to test the efficiency, of two different light-based disinfection treatments, namely UVB and UVC irradiation, on $P$. aeruginosa biofilms at different growth stages. In our experiments a new type of UV light emitting diodes (LEDs) were used to deliver UV irradiation on the biofilms, in the UVB (296nm) and UVC (266nm) region. The killing rate was studied as a function of dose for $24 \mathrm{~h}$ grown biofilms. The dose was ramped from $72 \mathrm{~J} / \mathrm{m} 2$ to $10000 \mathrm{~J} / \mathrm{m} 2$. It was shown that UVB irradiation was more effective than UVC irradiation in inactivating $P$. aeruginosa biofilms. No colony forming units (CFU) were observed for the UVB treated biofilms when the dose was $10000 \mathrm{~J} / \mathrm{m} 2$ (CFU in control sample: $7.5 \times 10^{4}$ ). UVB irradiation at a dose of $20000 \mathrm{~J} / \mathrm{m} 2$ on mature biofilms ( $72 \mathrm{~h}$ grown) resulted in a 3.9 log killing efficacy. The fact that the wavelength of $296 \mathrm{~nm}$ exists in daylight and has such disinfection ability on biofilms gives new perspectives for applications within disinfection at hospitals.
\end{abstract}

Keywords: Disinfection, Ultraviolet light, UVC, UVB, light emitting diodes (LEDs), Pseudomonas aeruginosa ( $P$. aeruginosa), sterilization.

\section{INTRODUCTION}

Biofilm-contaminated medical devices are believed to be a common cause for hospital acquired infections ${ }^{1}$. Moreover, biofilms are implicated in chronic infections such as chronic wounds and tissue filler-, implant- and catheter-associated infections ${ }^{2}$. Traditionally microbial infections are treated by antibiotics that inhibit the expansion of the contaminated area or kill the microbe ${ }^{3}$. However the problem with this approach is that antibiotic resistance is developed ${ }^{4}$. Furthermore, biofilms exhibit greater tolerance to antibiotics and antimicrobial stressors than planktonic organisms of the same species ${ }^{5}$. As a consequence researchers have turned their interest towards alternative disinfection approaches, including bacteriophage ${ }^{6}$, bacteriocins ${ }^{7}$ and light based treatments ${ }^{8}$. Ultraviolet (UV) radiation ${ }^{9,10}$, photodynamic therapy ${ }^{11,12}$, blue $e^{13,14}$ and near infrared light ${ }^{15,16}$ have been reported to have the advantage of non-invasiveness and the ability to inactivate microorganisms. Moreover, the expectation that the bacteria will develop light-resistant genes is low. ${ }^{8}$. On the other hand, light-based solutions demand effective light delivery. Thus, the potential applications are confined by penetration depth of light to the region of interest. For this reason, branches of medicine like dermatology and dentistry were the first to adopt the technology, due to the easier optical access to the region of interest.

*aikar@fotonik.dtu.dk; phone 0045-46774525; 
In this work the efficiencies of two different light-based disinfection treatments were tested, namely UVB and UVC irradiation, on $P$. aeruginosa biofilms at different growth stages. Their antibacterial action was studied as a function of dose. The survival curves were modelled using GInaFiT $^{17}$, a freeware tool to assess non-log-linear microbial survivor curves.

\section{MATERIALS AND METHODS}

\subsection{UV Irradiation system}

UV light emitting diodes (LEDs) were used to deliver UV irradiation on the biofilms, in the UVB (296nm) and UVC $(266 \mathrm{~nm})$ region. The setup for exposure of the biofilms is shown in Fig. 1a. The distance between the biofilm and the light sources was kept constant in all exposures. The spectral power distribution of the irradiation sources is shown in Fig. 1b. The LEDs were purchased from Sensor Electronic Technology, Inc (SETi, Columbia, SC, USA; TO3 package, hemispherical lens window, half angle of 20-25 degrees). Details about the irradiance measurements protocol and the setup can be found in Barnkob et al. ${ }^{18}$.

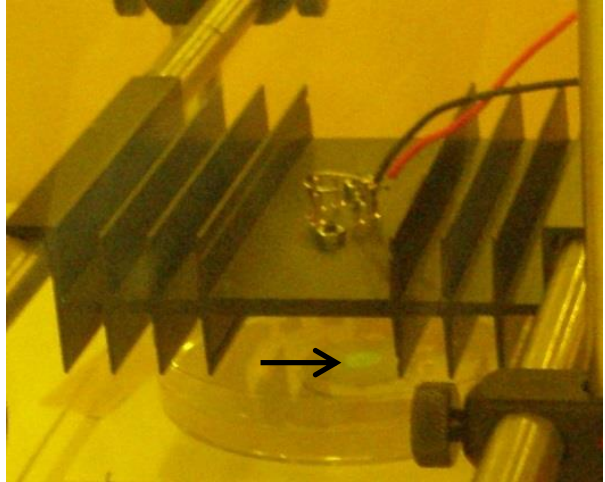

(a)

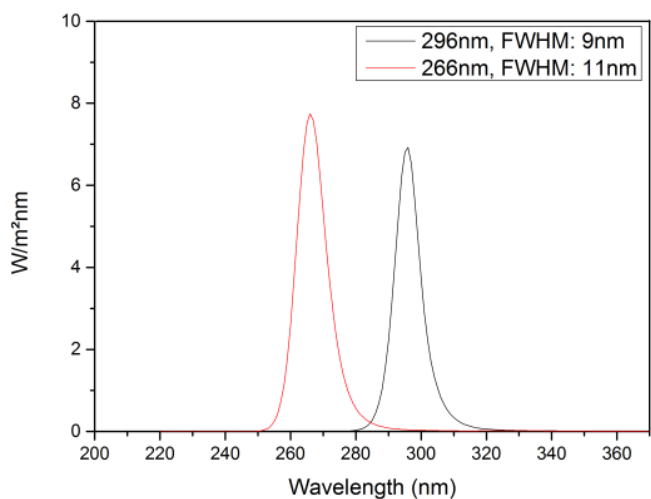

(b)

Figure 1. (a): The setup for exposure of biofilms to UVB and UVC irradiation, using LEDs. The biofilm is fluorescing under UV irradiation (greenish spot on the agar plate, arrow) (b): Spectral irradiance of the UVC (red curve) and UVB LEDs (black curve) used for the irradiation of the biofilms.

\subsection{Biofilm preparation}

The biofilms were grown on AB-trace glucose $(0.5 \%)$ and incubated for 24 hours (h) and $72 \mathrm{~h}$ at $37^{\circ} \mathrm{C}$. The $P$. aeruginosa (strain PAO1) used for the experiments was purchased from the Pseudomonas Genetic Stock Center (www.pseudomonas.med.ecu.edu). The biofilm was plated on cellulose nitrate membrane filters (Whatman ${ }^{\mathrm{TM}}$ ). The biofilms were kept in a UV free environment before the exposures. The biofilm was visible with naked eye and was fluorescing under UV exposure (see Fig. 1a, arrow). For a mature biofilm to develop ( $72 \mathrm{~h}$ grown), the membrane filter (containing the developing biofilm) was cautiously released and transferred to a fresh, agar plate every $24 \mathrm{~h}$. In this way the biofilm had access to fresh media and enabled a growth comparable to biofilm growth attained by more complicated methods ${ }^{19}$.

\subsection{Colony forming units (CFU)}

After the UV exposure, the (biofilm) plated cellulose nitrate membrane filters were immersed in sterile saline and degassed for 5 min before 5 min ultra-sonication. Serial dilutions (tenfold dilution for each step, 8 steps) were made and plated onto lysogeny broth medium. Control samples, i.e. biofilms which were not exposed to UV irradiation, were plated every hour and included in the study (tenfold dilutions, 8 steps); as a reference for growth (Fig. 2). All samples after treatment were kept in a UV free environment. CFUs for determining growth were counted after 24h of incubation 
in the dark at $37^{\circ} \mathrm{C}$. Zero counts of CFUs on all replicas after treatment were indicating total disinfection. Note that CFUs are per ml.

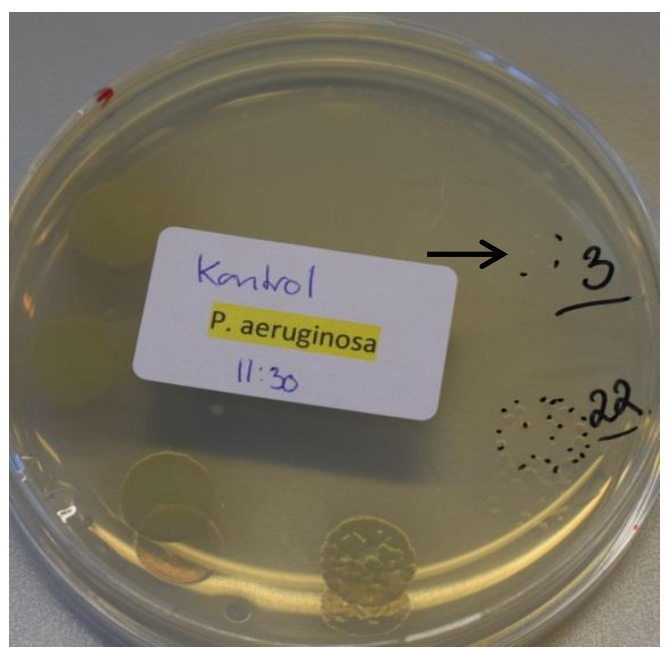

Figure 2. Picture of control sample serial dilutions' generated at 11:30. The control samples (not UV exposed) are used as a reference for growth. At higher dilutions, countable and well separated colony forming units were formed (arrow).

\subsection{Experimental design}

The objective was to determine how UV range (UVB versus UVC) and dose influence the viability of $P$. aeruginosa biofilms. The dose was ramped from $72 \mathrm{~J} / \mathrm{m} 2$ to $10000 \mathrm{~J} / \mathrm{m} 2$. The total irradiance among the different doses was varied between $18,6 \mathrm{~W} / \mathrm{m} 2$ and 108,4 W/m2 with the UVC diode. All UVC exposures lasted less than 1 minute and 32 seconds. For the UVB diode the total irradiance was varied between $1 \mathrm{~W} / \mathrm{m} 2$ and $14,8 \mathrm{~W} / \mathrm{m} 2$. In all UVB treatments the exposure time was less than 12 minutes (clinical treatment should not exceed 15 minutes for convenience). All tests, on $24 \mathrm{~h}$ and $72 \mathrm{~h}$ grown biofilms, were repeated respectively 3 and 2 times (triplet or doublet determination).

\subsection{Modelling of biofilm survival curves}

GInaFiT $^{17}$, (Geeraerd and Van Impe Inactivation Model Fitting Tool), a freeware Add-inn for Microsoft ${ }^{\circledR}$ Excel, was used to model the biofilm survival curves. The tool supports testing of nine types of microbial survival models, and five statistical measures (i.e., sum of squared errors, mean sum of squared errors and its root, R2, and adjusted R2) are provided to monitor the best fit ( $f$ function). Here, a choice of five suitable models ${ }^{20-24}$ was applied to the mean values of log survival (obtained from experimental data):

$$
\log \text { survival }=\log \left(\mathrm{N}_{\text {treated }} / \mathrm{N}_{\text {control }}\right)=f(\text { dose })
$$

where $\mathrm{N}_{\text {treated }}$ is the number of CFUs after a UV fluence $\left(\mathrm{J} / \mathrm{m}^{2}\right)$ is delivered to the biofilm, $\mathrm{N}_{\text {control }}$ is the number of CFUs on the controls (not UV exposed). Since $\log (0)$ is not defined; when zero counts are observed in $\mathrm{N}_{\text {treated }} \log$ survival is equal to $-\mathrm{x}$, where $\mathrm{x}$ is the order of magnitude of the $\mathrm{N}_{\text {control }}$ (example if $\mathrm{N}_{\text {control }}$ is of the order $10^{6}$, and $\mathrm{N}_{\text {treated }}$ had zero counts, $\log$ survival=-6).

\section{RESULTS}

\subsection{UVB antibacterial action}

The $\log$ survival values of $P$. aeruginosa biofilms, after being exposed to UVB irradiation (see spectral power distribution in Fig. 1b, black curve) with a central wavelength at $296 \mathrm{~nm}$, as a function of UV fluence (dose) are presented in Fig. 3a. Most models demonstrated a good fit to the experimental data $\left(R^{2} \geq 0,9\right)$ except the linear model ${ }^{20}$. The "biphasic" mode ${ }^{24}$ fitted best to the data (Fig. 3a). Though, this model requests minimal 10 points for assuring validity. The statistical measures of the models applied are presented in Table 1. If we use the concept of reliability engineering the reliable dose $d_{R}^{25}$ (dose needed to reduce number of microorganisms by a factor of 10) is calculated to be 
$638 \mathrm{~J} / \mathrm{m}^{2}$ (from the "Weibull model" the hazard rate was found to be $\alpha=54,86$ and the shape parameter $\beta=0,34$ ). The GInaFiT tool predicts that the needed dose for achieving a $4 \log$ reduction in the CFUs is $1900 \mathrm{~J} / \mathrm{m}^{2}$, in accordance with the experimentally observed value (at $2000 \mathrm{~J} / \mathrm{m} 2,4.1 \log$ reduction). No CFU were observed when a dose of $10000 \mathrm{~J} / \mathrm{m}^{2}$ was delivered to the biofilm, indicating total disinfection. Mature biofilms (grown for $72 \mathrm{~h}$ ) were much more resistant to the UVB treatment (Fig. 3b). A dose of $20000 \mathrm{~J} / \mathrm{m} 2$ on mature biofilms ( $72 \mathrm{~h}$ grown) resulted in a 3.9 log reduction. Higher resistance of mature $P$. aeruginosa biofilms (grown for $48 \mathrm{~h}$ ) has also been reported with various antibiotic treatments (tobramycin, colistin, ciproflox) ${ }^{19}$.

\subsection{UVC antibacterial action}

The antibacterial action of UVC irradiation, as a function of UV fluence (dose), with a power spectral distribution as shown in Fig. 1b (red curve) is shown in Fig. 4. The "biphasic" model fitted best to the data (not shown). From the "Weibull model ${ }^{22 "}$ (Fig. 4) with $\alpha=9870$ and $\beta=0,44$ the reliable dose $d_{R}{ }^{25}$ was calculated to be $65722 \mathrm{~J} / \mathrm{m}^{2}$. The statistical measures of the models applied are shown in Table 1. The GInaFiT tool in this case was unable to predict the needed dose for achieving a $4 \log$ reduction (maximum reduction achieved experimentally was $\log 1$ ).

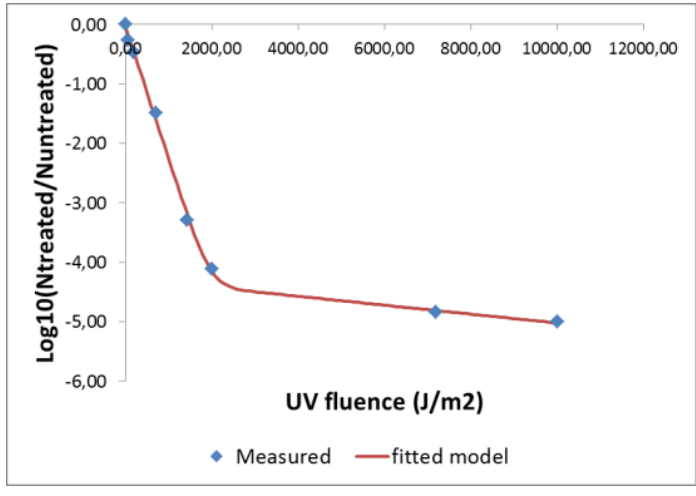

(a)

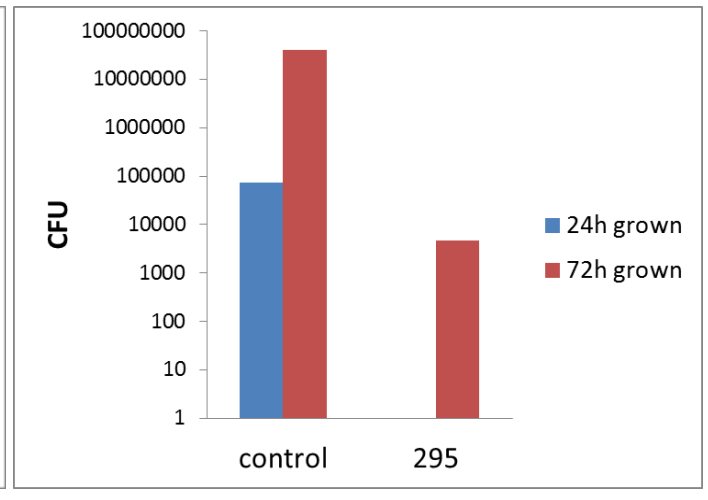

(b)

Figure 3.(a): UVB fluence dependent antibacterial action on $P$. aeruginosa biofilms. "Biphasic model" fitted exceptionally to the experimental data (statistical measures of fitted models presented in Table 1). However, this model requires minimal 10 points for assuring validity. (b): Comparison of effectivity of UVB treatment on mature-72h grown (blue columns) and non-mature-24h grown (red columns) $P$. aeruginosa biofilms. Total disinfection from a non-mature biofilm was achieved with a dose of $10000 \mathrm{~J} / \mathrm{m}^{2}$. A dose of $20000 \mathrm{~J} / \mathrm{m}^{2}$ resulted in a $3.9 \log$ reduction on mature biofilms.

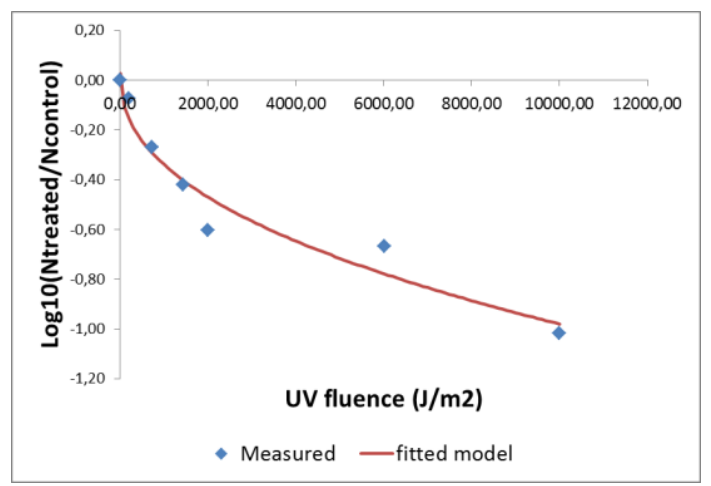

Figure 4. UVC fluence dependent antibacterial action on P. aeruginosa biofilms (experimental data and Weibull fit). 
Table 1. Statistical measures of the models applied to the experimental data for log reduction of $P$. aeruginosa by UVB (and UVC).

\begin{tabular}{|c|c|c|c|c|c|c|}
\hline Fitted model & MSE & RMSE & $\mathbf{R}^{2}$ & $\begin{array}{c}\mathbf{R}^{2}- \\
\text { adjusted }\end{array}$ & SSE & $\begin{array}{c}D \\
4 \log \end{array}$ \\
\hline Log-linear & $\begin{array}{l}1,6 \\
(0,03)\end{array}$ & $\begin{array}{l}1,28 \\
(0,16)\end{array}$ & $\begin{array}{l}0,69 \\
(0,84)\end{array}$ & $\begin{array}{l}0,63 \\
(0,80)\end{array}$ & $\begin{array}{l}9,84 \\
(0,13)\end{array}$ & $\begin{array}{l}8700 \\
\text { (NA) }\end{array}$ \\
\hline Weibull & $\begin{array}{l}0,60 \\
(0,01)\end{array}$ & $\begin{array}{l}0,78 \\
(0,1)\end{array}$ & $\begin{array}{l}0,90 \\
(0,95)\end{array}$ & $\begin{array}{l}0,87 \\
(0,92)\end{array}$ & $\begin{array}{l}2,99 \\
(0,04)\end{array}$ & $\begin{array}{l}3300 \\
\text { (NA) }\end{array}$ \\
\hline Biphasic & $\begin{array}{l}0,01 \\
(0,01)\end{array}$ & $\begin{array}{l}0,09 \\
(0,08)\end{array}$ & $\begin{array}{l}0,9989 \\
(0,98)\end{array}$ & $\begin{array}{l}0,9980 \\
(0,95)\end{array}$ & $\begin{array}{l}0,04 \\
(0,02)\end{array}$ & $\begin{array}{l}1900 \\
\text { (NA) }\end{array}$ \\
\hline Log+tail & $\begin{array}{l}0,014 \\
(0,02)\end{array}$ & $\begin{array}{l}0,12 \\
(0,12)\end{array}$ & $\begin{array}{l}0,9978 \\
(0,92)\end{array}$ & $\begin{array}{l}0,9970 \\
(0,88)\end{array}$ & $\begin{array}{l}0,07 \\
(0,06)\end{array}$ & $\begin{array}{l}1900 \\
\text { (NA) }\end{array}$ \\
\hline $\begin{array}{l}\text { Albert } \\
\text { (Weibull+tail) }\end{array}$ & $\begin{array}{l}0,017 \\
\text { (NA) }\end{array}$ & $\begin{array}{l}0,13 \\
\text { (NA) }\end{array}$ & $\begin{array}{l}0,9978 \\
\text { (NA) }\end{array}$ & $\begin{array}{l}0,9960 \\
\text { (NA) }\end{array}$ & $\begin{array}{l}0,07 \\
(\mathrm{NA})\end{array}$ & $\begin{array}{l}1900 \\
\text { (NA) }\end{array}$ \\
\hline
\end{tabular}

\section{DISCUSSION}

In the present study we characterized the disinfection efficacies of $P$. aeruginosa biofilms (strain PAO1) under narrowband UVB (central wavelength 296nm, FWHM 9nm) and UVC (central wavelength 266nm, FWHM 11nm) irradiation. It was demonstrated that narrowband UVB at $296 \mathrm{~nm}$ is more efficient in killing the biofilms, than narrowband UVC at $266 \mathrm{~nm}$. To the contrary, several studies have shown in the past that UVC irradiation is much more effective than UVB in eliminating bacteria in solution ${ }^{26,27}$. When the bacteria are in planktonic state it is expected that the penetration of light will be much different, than in a biofilm where bacteria are aggregated and embedded in the extracellular polymeric matrix (EPS) ${ }^{28}$. Nevertheless, the defense mechanisms in a biofilm are more sophisticated due to processes like quorum sensing ${ }^{29,30}$. So investigations for determining the killing efficiency of various treatments against biofilms have special interest. Disinfection of catheter biofilms has been successfully reported by UVC LEDs ${ }^{31}$. To our knowledge, the ability to eliminate a biofilm grown for $24 \mathrm{~h}$ and $72 \mathrm{~h}$, with UVB LEDs (narrowband spectral power distribution), has not previously been reported. Studies on the response of biofilm bacterial communities to various ranges of UV radiation (namely UVC, UVB and UVA) have been demonstrated before ${ }^{32}$ with broadband light sources and have shown that UVC is more effective than UVB, while UVA has a significant effect only when photosensitizers

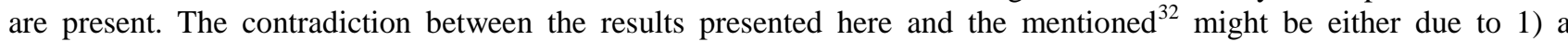
different formation of the biofilms or 2) due to the differences between narrowband and broadband irradiation (or both 1 and 2).

Modelling of the dose dependent killing of the $P$. aeruginosa biofilms with UVC and UVB light showed that a log-linear model (based on first-order kinetics) failed to fit the experimental data and provide a satisfactory estimate for the needed dose for achieving a 4log CFU reduction. On the contrary, more complex models that take into account a "shift of behavior" (Weibull, biphasic, log+tail, Albert) for a subgroup of bacteria succeeded to fit to the experimental data $\left(\mathrm{R}^{2} \geq 0,9\right)$. Moreover, the "Weibull model was adequate for giving a rough estimation/prediction (correct order of magnitude) of the reliable dose $d_{R}$, for both UVB and UVC treatments. Weibull models have been reported to successfully predict inactivation of Escherichia coli and Salmonella enterica after exposure to ozone or pulsed light $(100-1100 \mathrm{~nm})^{33}$. Finally, $\beta$ values were $<1$ both for UVB and UVC treatments meaning that there are some persistent bacteria in the biofilm that have less probability of being killed, perhaps because they adapt to the irradiation or because they are not as affected. e.g. due to limited penetration depth of light to the biofilm's deepest layers and/or due to the shielding effect of the EPS. 


\section{CONCLUSSION}

A $1 \log$ killing efficacy was achieved on P. aeruginosa biofilms for a dose of $10000 \mathrm{~J} / \mathrm{m} 2$ with the UVC diode, while the UVB diode achieved a $3 \log$ reduction at a dose of $1440 \mathrm{~J} / \mathrm{m} 2$ for the $24 \mathrm{~h}$ grown biofilms. No CFU were observed for the UVB treated biofilms when the dose was $10000 \mathrm{~J} / \mathrm{m} 2$ (CFU in control sample: $0,75 \times 10^{5}$ ). UVB irradiation, at a dose of $20000 \mathrm{~J} / \mathrm{m} 2$, on mature biofilms (72h grown) showed that CFU were reduced in average from $4.0 \times 10^{7}$ (untreated) to $4.65 \times 10^{3}$ (UVB treated), resulting in a $3.9 \mathrm{log}$ reduction. These results show that UVB irradiation was more effective than UVC irradiation in killing P. aeruginosa biofilms. The efficiency of killing by irradiation is reduced when the target biofilm is mature (left to grow for $72 \mathrm{~h}$ ). That supports the hypothesis about the importance of penetration depth, since mature biofilms create a thicker matrix expected to be less penetrable by light.

The log-linear model (based on first-order kinetics) failed to fit the experimental data. The shape parameter $(\beta)$ of the "Weibull model" was $<1$ both for UVB and UVC treatments meaning that there were some bacteria in the biofilm that had less probability of being killed.

The fact that the UVB irradiation (wavelength of $296 \mathrm{~nm}$ ) exists in daylight and has such disinfection ability on biofilms gives new perspectives for applications within disinfection at hospitals.

\section{REFERENCES}

[1] Guggenbichler, Josef Peter et al, "Incidence and Clinical Implication of Nosocomial Infections Associated with Implantable Biomaterials - Catheters, Ventilator-Associated Pneumonia, Urinary Tract Infections," GMS Krankenhaushygiene interdisziplinär 6 (1),1-19 (2011).

[2] Thomas Bjarnsholt, "The role of bacterial biofilms in chronic infections," APMIS 121( Issue Supplement s136), 1-58 (2013).

[3] Bryers, James D., "Medical Biofilms," Biotechnology and bioengineering 100 (1), 1-18 (2008).

[4] Geddes A., "Infection in the twenty-first century: Predictions and postulates," J. Antimicrob. Chemother 46 (6), 873-878 (2000).

[5] Van Leeuwenhoek A., "Microscopical observations about animals in the scurf of the teeth.," Philos Trans R Soc Lond B boil Sci 14, 568-74 (1684).

[6] Jassim, Sabah A. A., and Richard G. Limoges., "Natural Solution to Antibiotic Resistance: Bacteriophages 'The Living Drugs," World Journal of Microbiology \& Biotechnology 30 (8), 2153-2170 (2014).

[7] Cotter, Paul D., R. Paul Ross, and Colin Hill., "Bacteriocins - a viable alternative to antibiotics?," Nature Reviews Microbiology 11(2), 95-105 (2013).

[8] Yin, Rui, Tianhong Dai, Pinar Avci, Ana Elisa Serafim Jorge, Wanessa CMA de Melo, Daniela Vecchio, YingYing Huang, Asheesh Gupta, and Michael R. Hamblin., "Light based anti-infectives: ultraviolet C irradiation, photodynamic therapy, blue light, and beyond," Current opinion in pharmacology 13(5), 731-762 (2013).

[9] Thai, Thao P., Pamela E. Houghton, David H. Keast, Karen E. Campbell, and M. Gail Woodbury.,"ULTRAVIOLET LIGHT Cin THE TREATMENT OF CHRONIC WOUNDS WITH MRSA: ACase STUDY," Ostomy/wound management 48 (11), 52-60 (2002).

[10] Thai, Thao P., David H. Keast, Karen E. Campbell, M. Gail Woodbury, and Pamela E. Houghton., "Effect of ultraviolet light $\mathrm{C}$ on bacterial colonization in chronic wounds," Ostomy/wound management 51(10), 32-45 (2005)

[11] Hamblin, Michael R., and Tayyaba Hasan., "Photodynamic therapy: a new antimicrobial approach to infectious disease?," Photochemical \& Photobiological Sciences 3(5), 436-450 (2004).

[12] Maisch, Tim, J. Wagner, V. Papastamou, H-J. Nerl, K-A. Hiller, R-M. Szeimies, and Gottfried Schmalz., "Combination of $10 \%$ EDTA, Photosan, and a blue light hand-held photopolymerizer to inactivate leading oral bacteria in dentistry in vitro," Journal of applied microbiology 107(5), 1569-1578 (2009).

[13] Enwemeka, Chukuka S., Deborah Williams, Sombiri K. Enwemeka, Steve Hollosi, and David Yens, "Blue 470$\mathrm{nm}$ light kills methicillin-resistant Staphylococcus aureus (MRSA) in vitro," Photomedicine and laser surgery 27 (2), 221-226 (2009).

[14]Dai, Tianhong, Asheesh Gupta, Ying-Ying Huang, Rui Yin, Clinton K. Murray, Mark S. Vrahas, Margaret E. Sherwood, George P. Tegos, and Michael R. Hamblin, "Blue light rescues mice from potentially fatal 
Pseudomonas aeruginosa burn infection: efficacy, safety, and mechanism of action," Antimicrobial agents and chemotherapy 57(3), 1238-1245 (2013).

[15] Tsen KT, Fu TS, Lindsay Q, Kibler SM, Jacobs K, Wu B, Karanam TC, Jagu B, Roden SRB et al.,” Photonic approach to the selective inactivation of viruses with a near-infrared subpicosecond fiber laser," J Biomed Opt 14, 064042 (2009).

[16] Tsen, Kong T., Shaw-Wei D. Tsen, Otto F. Sankey, and Juliann G. Kiang, "Selective inactivation of microorganisms with near-infrared femtosecond laser pulses," Journal of Physics: Condensed Matter 19 (47), 472201 (2007).

[17] Geeraerd, A. H., V. P. Valdramidis, and J. F. Van Impe, "GInaFiT, a freeware tool to assess non-log-linear microbial survivor curves," International journal of food microbiology 102(1), 95-105 (2005).

[18] Line L. Barnkob, Aikaterini Argyraki, Paul M. Petersen, Jette Jakobsen, "Investigation of the effect of UVLED exposure conditions on the production of vitamin D in pig skin," submitted in Food Chemistry (15-12-15).

[19] Camilla Stavnsbjerg, M. Alhede1,2, A. K. Nielsen1, K. Qvortrup1, T. H. Jakobsen1, T. Tolker-Nielsen1, N. Høiby2, M. Givskov1, T. Bjarnsholt2." An easy and cheap biofilm setup for fast screening of different biofilm phenotypes," to be submitted.

[20] W.D. Bigelow and J.R. Esty, "The thermal death point in relation to typical thermophylic organisms," Journal of Infectious Diseases 27, 602 (1920).

[21] A.H. Geeraerd, C.H. Herremans and J.F. Van Impe, "Structural model requirements to describe microbial inactivation during a mild heat treatment," International Journal of Food Microbiology 59(3), 185-209 (2000).

[22] P. Mafart, O. Couvert, S. Gaillard and I. Leguerinel," On calculating sterility in thermal preservation methods: application of the Weibull frequency distribution model," International Journal of Food Microbiology 72, $107-$ 113 (2002).

[23] I. Albert and P. Mafart, “A modified Weibull model for bacterial inactivation,” International Journal of Food Microbiology 100, 197-211 (2005).

[24] Cerf O., "Tailing of survival curves of bacterial spores,” Journal of Applied Bacteriology 42, 1-19 (1977).

[25] Martinus A.J.S. van Boekel, "On the use of the Weibull model to describe thermal inactivation of microbial vegetative cells, ” International Journal of Food Microbiology 74, 139- 159 (2002).

[26] A. L. Santos, V. Oliveira, I. Baptista, I. Henriques, N. C. M. Gomes, A. Almeida, A. Correia, A. Cunha, "Wavelength dependence of biological damage induced by UV radiation on bacteria," Arch Microbiol 195, 6374 (2013).

[27] Mamane-Gravetz, Hadas, Karl G. Linden, Alexander Cabaj, and Regina Sommer, "Spectral sensitivity of Bacillus subtilis spores and MS2 coliphage for validation testing of ultraviolet reactors for water disinfection," Environmental science \& technology 39 (20), 7845-7852 (2005).

[28] Flemming, Hans-Curt, and Jost Wingender, "The biofilm matrix," Nature Reviews Microbiology 8(9), 623-633 (2010).

[29] Bjarnsholt, Thomas, and Michael Givskov, "Quorum-sensing blockade as a strategy for enhancing host defences against bacterial pathogens," Philosophical Transactions of the Royal Society of London B: Biological Sciences 362(1483), 1213-1222 (2007).

[30] Skindersoe, Mette Elena, Piers Ettinger-Epstein, Thomas Bovbjerg Rasmussen, Thomas Bjarnsholt, Rocky de Nys, and Michael Givskov,"Quorum sensing antagonism from marine organisms," Marine Biotechnology 10(1), 56-63 (2008).

[31] Bak, Jimmy, Søren D. Ladefoged, Michael Tvede, Tanja Begovic, and Annette Gregersen, "Dose requirements for UVC disinfection of catheter biofilms," Biofouling 25 (4), 289-296 (2009).

[32] Elasri, Mohamed O., and Robert V. Miller, "Study of the response of a biofilm bacterial community to UV radiation," Applied and Environmental Microbiology 65(5), 2025-2031 (1999).

[33] Bialka, Katherine L., Ali Demirci, and Virendra M. Puri, "Modeling the inactivation of Escherichia coli O157: H7 and Salmonella enterica on raspberries and strawberries resulting from exposure to ozone or pulsed UVlight," Journal of Food Engineering 85 (3), 444-449 (2008). 